\title{
A MARKOV MODEL OF THE NATURAL HISTORY OF PROSTATE CANCER
}

\author{
Mark E. Cowen, ${ }^{1,2 *}$ Michael Chartrand ${ }^{1}$ and William F. Weitzel ${ }^{1,2}$ \\ 'Department of Medicine, St Joseph Mercy Hospital and ${ }^{2}$ University of Michigan Medical School, \\ Ann Arbor, MI 48106, U.S.A.
}

(Received 4 May 1993)

\begin{abstract}
The objective of this study was to lay a foundation for future cost-benefit analyses evaluating the public health impact of treatment and screening protocols for prostate cancer. Specifically we wanted to define the relative impact on cancer-specific mortality rates of the individual epidemiological components: pathological incidences by age groups, cancer progression rates, and the effect of competing causes of death, assuming expectant management (i.e. no definitive treatment). A biological model of prostate cancer incidence and progression was converted into a standard Markov tree where competing causes of death could occur. Weighted averages of progression rates were obtained from clinical studies. Separate cohorts of 30 year old black and white men were followed for 50 years. The model yielded cancer-specific mortality rates, overall mortality rates, and pathologic prevalences for both white and black males, consistent with the literature. Sensitivity analyses showed that of all the parameters studied, the pathological incidence of cancer in men under 50 years of age had the greatest impact on the cancer-specific mortality rates. Also important was the annual probability of progression of Al lesions. However the other parameters including pathological incidence in older males, and progression from locally-extensive to metastatic lesions had much smaller effects. In summary, this model correlates the clinical literature with the epidemiology of prostate cancer and can be used for further decision analyses. We recommend that future research be done to more precisely quantify the pathological incidence of prostate cancer in men under 50-60 years of age. More certainty is also needed before generalizing the results of relatively small Al series to millions of men, since $\mathrm{A} 1$ progression rates critically affect the eventual cancer-specific mortality. Enough uncertainty remains at this point however, that we cannot advocate widespread screening for prostate cancer until its merit be demonstrated either by the definitive long term study, or by examination of costs and quality-of-life-adjusted benefits.
\end{abstract}

Prostate Cancer Computer simulation Natural history Decision analysis Clinical epidemiology

\section{INTRODUCTION}

Prostate cancer provokes controversies in diagnosis, management, and early detection because its natural history is poorly understood [1]. Newer screening modalities and treatment protocols could potentially affect millions of Amer-

*All correspondence should be addressed to: Mark E. Cowen, M.D., St Joseph Mercy Hospital, P.O. Box 995, Ann Arbor, MI 48106, U.S.A. ican men at a cost of billions of dollars [2] since it is the most common non-skin carcinoma [3] in males.

We have developed a Markov model [4] to simulate the clinical epidemiology of prostate cancer. This model starts with the pathological incidence in various ages and follows the cancer progression through the various stages until death occurs either from prostate cancer or from other competing causes. We derived the 
progression rates from familiar studies in the literature-flawed though they be, since various clinical papers have and will continue to be used as support or rejection for recommendations for the ideal treatment or mode of screening for prostate cancer.

Undoubtedly individual tumors can progress rapidly [5], and the course of individual patients varies, but these may not accurately represent the larger population with prostate cancer. It is possible that a subset of patients, as described in a particular clinical study, may have a progression rate so large that if it were representative of all patients within a given stage, many more deaths due to prostate cancer would occur than seems possible given the current annual mortality figures. By the same token, if one believes a low progression rate, why is it that many men do progress and die? An epidemiological model such as ours can help reconcile these differences by estimating what an average progression rate of a stage would have to be in order to obtain realistic mortality figures. It is also possible via sensitivity analyses, to determine which age-specific incidences or stage progression rates would most affect the cancerspecific mortality of the population. This information could then be used for further cost benefit analyses, and to help design further clinical studies. Although we cannot yet use this model to determine the merits of screening, we believe the model needs to be presented now in its current form to relate the complex prostate literature to the actual public health problem of prostate cancer.

Before we describe the methodology used in the development of the model, we want to summarize some of the problems with the prostate literature. These flaws certainly weaken our model and any model based on these studies, yet they also underscore the need for such a model to help reconcile the apparent contradictions. Strongly held opinions stem from publications of small series of treated patients, the use of non-comparable historical controls [6], differences in treatment settings (referral centers vs community hospitals) [7], definitions of progression/treatment failures, and methods and duration of follow-up [6, 8]. Another important basis for the controversies is the effect of competing causes of death. The prevalence of prostate cancer is highest in older men [9], most of whom die of other causes [6], given the relativcly smaller cancer-specific mortality rates reported by the Surveillance, Epidemiology, and

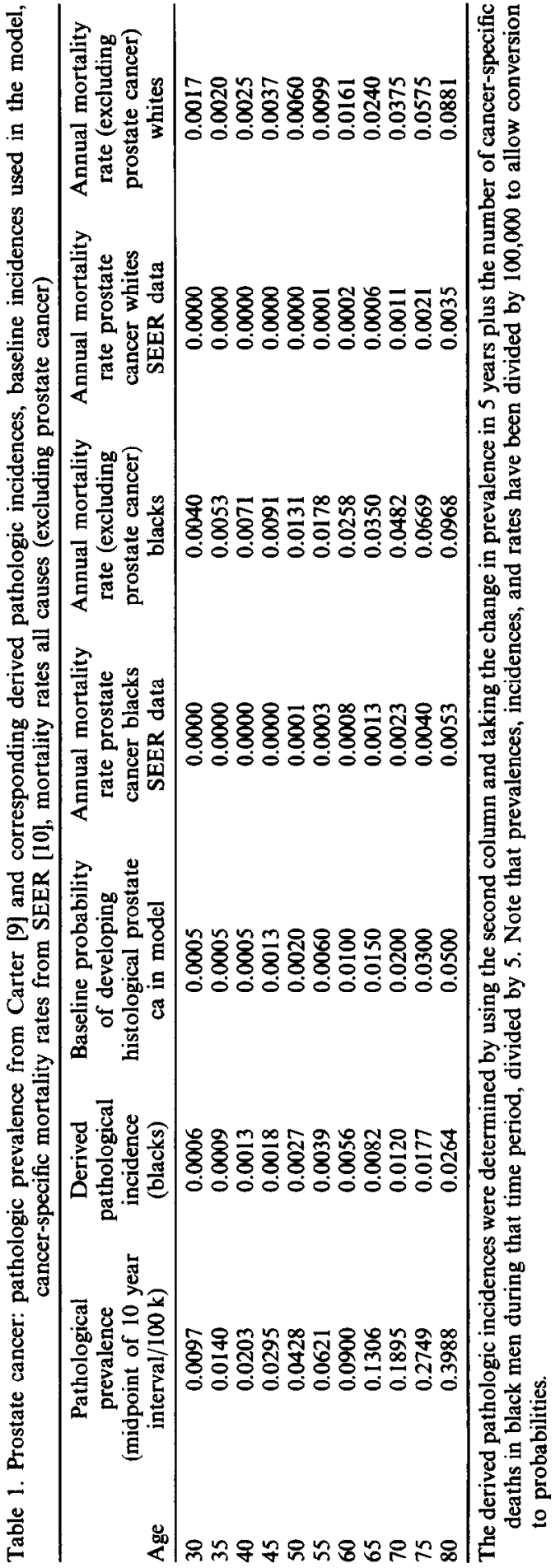


End Results (SEER) Program [10], shown in our Table 1. It is also difficult to compare results from one paper to the next, since similar patients may be staged differently $[11,12]$. Donohue compiled several series and found that the following clinical stages had the corresponding mean fractions of metastatic lymph node involvement found post-operatively [12]: $\mathrm{A} 1$ 0.02, A2 0.19, B1 0.11, B2 0.29, B 0.22, C 0.46. To make matters even more confusing, even within the same stage, the extent of capsular perforation $[8,13-15]$, and the degree of tumor differentiation [16] can affect the prognosis. Faced with the clinical literature so huge and flawed, one may well choose a nihilistic approach which rejects the literature and waits for the definitive prospectively, randomized, controlled study of screened vs non-screened men. This may take time given the multiple choices of therapy and the rapid development of new screening tools. Furthermore, the older studies in the literature will continue to be cited to support a given treatment or approach. We have chosen to be neither nihilistic or naive, and have tried a pragmatic approach: can we somehow develop a model that refers to the literature, and make some assumptions with the goal of better understanding the public health problem of prostate cancer?

\section{METHODS}

Papers were identified using Paper Chase and the bibliographies were reviewed.

\section{Classification system used}

According to the American Urological Society system [17],

Stage $A$ are non-palpable, "clinically inapparent" [18] tumors traditionally found unexpectedly after transurethral resections, subdivided into stage Al (tumor comprising less than $5 \%$ of the gland and usually well-differentiated) and A2 (tumor involving more than $5 \%$ of the gland, usually more aggressive and less-differentiated [19]).

Stage $B$ lesions are palpable, localized prostate cancers confined to the gland, sometimes further subdivided into B1 or B2 depending on the size [17].

Stage $C$ tumors are locally extensive but have not metastasized, and can be subdivided into $\mathrm{Cl}$ or $\mathrm{C} 2$ lesions [17].
Stage $D$ or metastatic tumors are divided into D1 lesions which represent lymph node involvement, and D2 which reflect the presence of distant metastases, usually bony [17].

\section{Formulas for progression rates and probabilities}

Many papers reported their data differently. To standardize the measurements, we converted information into standard units: annual mortality rate, annual rate of formation of distant metastases, and annual rate of becoming locally cxtensive. Wc distinguished the site where progression or treatment failure was first noticed, either local progression to a $C$ lesion or distant progression to a D2 lesion. For example if an $\mathrm{A} 2$ lesion became a $\mathrm{C}$ lesion within a 5 year period and later became a D2 lesion at year 10 , we would count it as first progressing to a $\mathrm{C}$ lesion (and not double-count it as a D2). If on the other hand the first sign of progression was a bony metastasis, then we considered it as first progressing distantly to $\mathrm{D} 2$ and not to stage $\mathrm{C}$. We excluded papers if we could not distinguish their initial stage (e.g. Ref. [20]), or if the progressions could not be categorized (e.g. Refs [21], [22], [23]). We derived the rates using the following basic formulas which assume an exponential survival curve [24]:

mortality rate $=-1 /$ time $* \ln [$ fraction not dying]

rate of becoming $\mathrm{C}=-1 /$ time* $\ln [$ fraction not first becoming a $\mathrm{C}$ lesion]

rate of becoming $\mathrm{D} 2=-1 /$ time $* \ln [$ fraction not first becoming a D2 lesion]

Since many prostate cancer deaths occur in the elderly who can die from other causes, it is important when evaluating a series to identify cancer-specific deaths. We tried to use "diseasespecific" mortality data if directly reported, or if not available, then approximated by the following formula [24]:

disease specific mortality rate $=$ (crude rate) (expected rate)

The derived rates were then converted into annual probabilities by using [25]:

$$
\text { probability }=1-\exp (-r t)
$$

where $r$ is the rate (of mortality, or of local progression or of distant progression) and $t$ is the time in which an event will occur, which is one year in our model. 
Derivation of probability of developing prostate cancer

We used the estimated pathological prevalence of prostate cancer from a graph of prevalence vs age by Carter [9]. This paper was chosen since it was a compilation from the literature of 5250 autopsies with careful "step-section" technique. The indicated ages represent the beginning of 10 year intervals $[H$. B. Carter, personal communication]. From that graph we defined a curve using the statistical software package Systat (Wilkinson, Leland. SYSTAT: The System for Statistics. Evanston, IL: SYSTAT, Inc.; 1990), and estimated the pathological incidence as the difference in prevalence per 100,000 males over a 5 year interval, plus the deaths due to prostate cancer as reported in the SEER study [10], shown in Table 1. The derived incidence rates were converted into annual probabilities of developing prostate cancer at a given age, then adjusted for use in the baseline analysis in order to yield the prevalences in Fig. 6 .

\section{Clinical Studies (Tables 3 to 10)}

Studies within similar stages were combined in order to calculate "weighted averages". We viewed these derived numbers as only rough estimates, since we are not confident of how similar these groupings are, given the problems inherent in the prostate literature. For this reason, we did not feel further statistical analyses on variance was meaningful. The American College of Surgeons (ACS) series [7] was not included in the calculations of the "weighted averages" since it was so much larger than the other papers, and since many of its 20,661 clinically-staged patients received treatment. (The treatment given could theoretically lower the mortality rates compared to untreated patients, but clinical staging means there was probably inclusion of patients with positive lymph nodes which might raise the expected mortality rates.) Although our focus was on untreated (or delayed, or non-curatively treated) patients, we listed some series of treated patients

Table 2. Baseline values and results of selected sensitivity analyses for whites

\begin{tabular}{|c|c|c|c|c|c|}
\hline $\begin{array}{l}\text { Parameter } \\
\text { of } \\
\text { interest }\end{array}$ & $\begin{array}{l}\text { Baseline } \\
\text { value } \\
\text { used }\end{array}$ & $\begin{array}{l}\text { Sensitivity } \\
\text { analysis } \\
\text { value }\end{array}$ & $\begin{array}{c}\text { Baseline } \\
\text { fraction } \\
\text { dead }\end{array}$ & $\begin{array}{c}\text { Sensitivity } \\
\text { analysis } \\
\text { fraction dead }\end{array}$ & $\begin{array}{l}\text { Sensitivity } \\
\text { index }\end{array}$ \\
\hline Start Al .01 & 0.0005 & 0.01 & 0.017 & 0.0225 & 0.58 \\
\hline \multirow[t]{2}{*}{$p \mathrm{CA} 40$} & 0.0005 & 0.001 & 0.017 & 0.0191 & 4.20 \\
\hline & 0.0005 & 0.002 & 0.017 & 0.0232 & 4.13 \\
\hline pCA50 & 0.002 & 0.003 & 0.017 & 0.0193 & 2.30 \\
\hline \multirow[t]{2}{*}{$p \mathrm{CA} 60$} & 0.01 & 0 & 0.017 & 0.0084 & 0.86 \\
\hline & 0.01 & 0.015 & 0.017 & 0.0203 & 0.66 \\
\hline pCA65 & 0.015 & 0 & 0.017 & 0.0154 & 0.11 \\
\hline pCA70 & 0.02 & 0 & 0.017 & 0.0168 & 0.01 \\
\hline \multirow[t]{6}{*}{$p \mathrm{~A} 1 \mathrm{~A} 2$} & 0.02 & 0.01 & 0.017 & 0.0075 & 0.95 \\
\hline & 0.02 & 0.015 & 0.017 & 0.0135 & 0.70 \\
\hline & 0.02 & 0.017 & 0.017 & 0.0149 & 0.70 \\
\hline & 0.02 & 0.03 & 0.017 & 0.023 & 0.60 \\
\hline & 0.02 & 0.04 & 0.017 & 0.0279 & 0.55 \\
\hline & 0.02 & 0.05 & 0.017 & 0.0319 & 0.50 \\
\hline \multirow[t]{2}{*}{$p \mathrm{BC}$} & 0.08 & 0.01 & 0.017 & 0.015 & 0.03 \\
\hline & 0.08 & 0.15 & 0.017 & 0.0183 & 0.02 \\
\hline \multirow[t]{2}{*}{$p \mathrm{BDl}$} & 0.1 & 0.01 & 0.017 & 0.0099 & 0.08 \\
\hline & 0.1 & 0.2 & 0.017 & 0.0212 & 0.04 \\
\hline \multirow[t]{2}{*}{$p \mathrm{CD} 1$} & 0.3 & 0.1 & 0.017 & 0.0146 & 0.01 \\
\hline & 0.3 & 0.4 & 0.017 & 0.0175 & 0.01 \\
\hline \multirow[t]{2}{*}{$p \mathrm{D} 1 \mathrm{D} 2$} & 0.34 & 0.3 & 0.017 & 0.0167 & 0.01 \\
\hline & 0.34 & 0.5 & 0.017 & 0.0187 & 0.01 \\
\hline \multirow[t]{2}{*}{$p$ DIE } & 0.26 & 0.2 & 0.017 & 0.0154 & 0.03 \\
\hline & 0.26 & 0.4 & 0.017 & 0.0193 & 0.02 \\
\hline \multicolumn{6}{|c|}{$\begin{array}{l}\text { Abhreviations: Start A1 } 01 \text {, starting prevalence of } 0.01 \text { for } 30 \text { year olds; } p C A 40, \\
p C A 50, p C A 60, p C A 70 \text { probabilities of developing prostate cancer at the age of } \\
40,50,60 \text { and } 70, p A 1 A 2 \text { probability of an A1 lesion progressing to an A2 lesion } \\
\text { in one year. This is also assumed to be equal to the probability of progression } \\
\text { to stage B. } p \mathrm{BC}, p \mathrm{BD} 1 \text { probability of B lesions progressing to C or D1 lesions. } \\
p \mathrm{CD} 1, \text { probability of progression from C to D1, } p \mathrm{D} 1 \mathrm{D} 2 \text {, progression from D1 } \\
\text { to } \mathrm{D} 2 . p \mathrm{DIE} \text { progression from } \mathrm{D} 2 \text { to death of prostate cancer. The baseline } \\
\text { fraction of } 0.17 \text { is the proportion of the original cohort that died of prostate } \\
\text { cancer at age } 75 \text {. The "Sensitivity Analysis Fraction" is the proportion of the } \\
\text { original cohort dying of prostate cancer that resulted from substituting the } \\
\text { indicated sensitivity analysis value in place of the parameter's baseline value. See } \\
\text { text for the definition of the "Sensitivity Index". }\end{array}$} \\
\hline
\end{tabular}




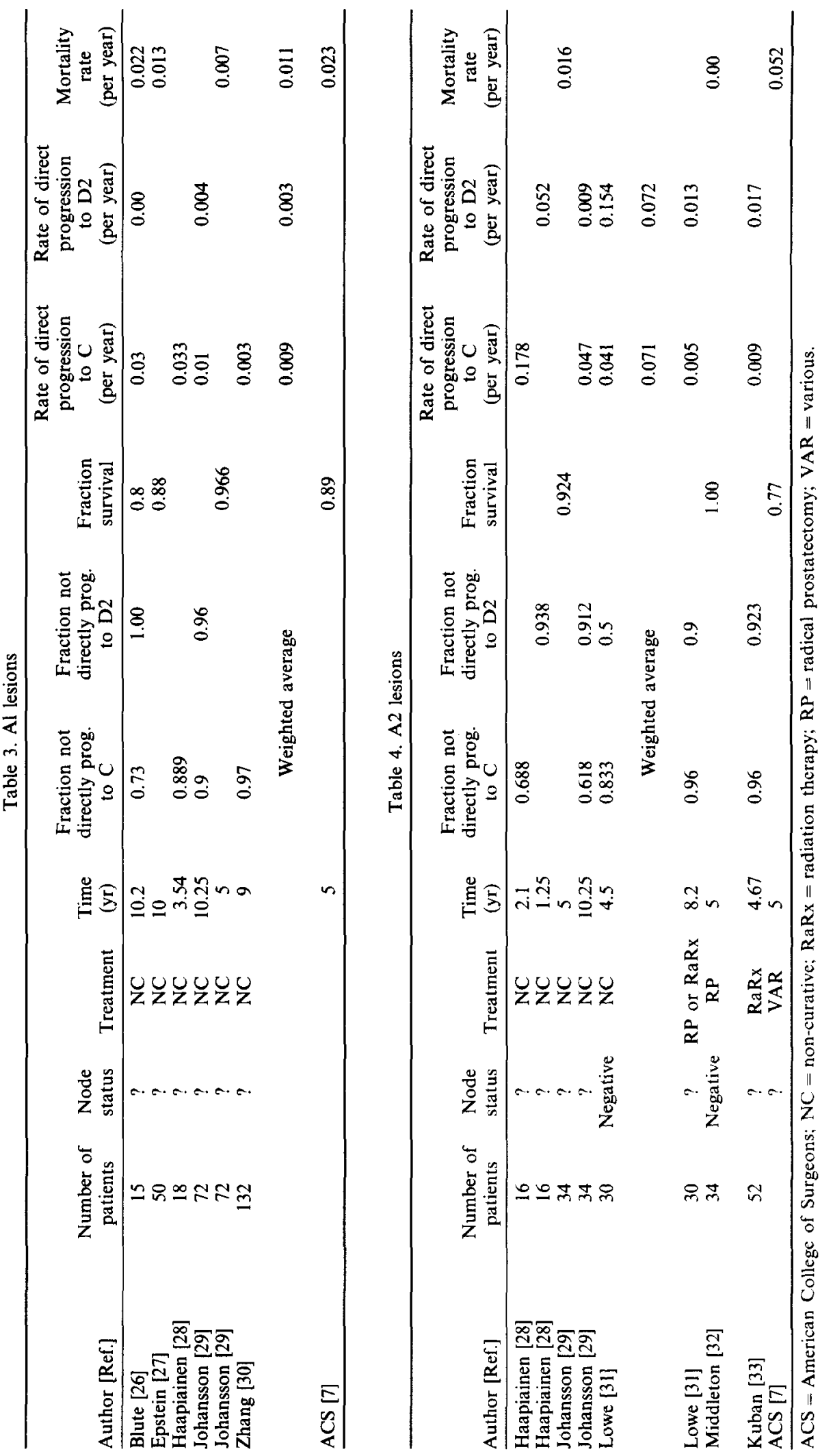




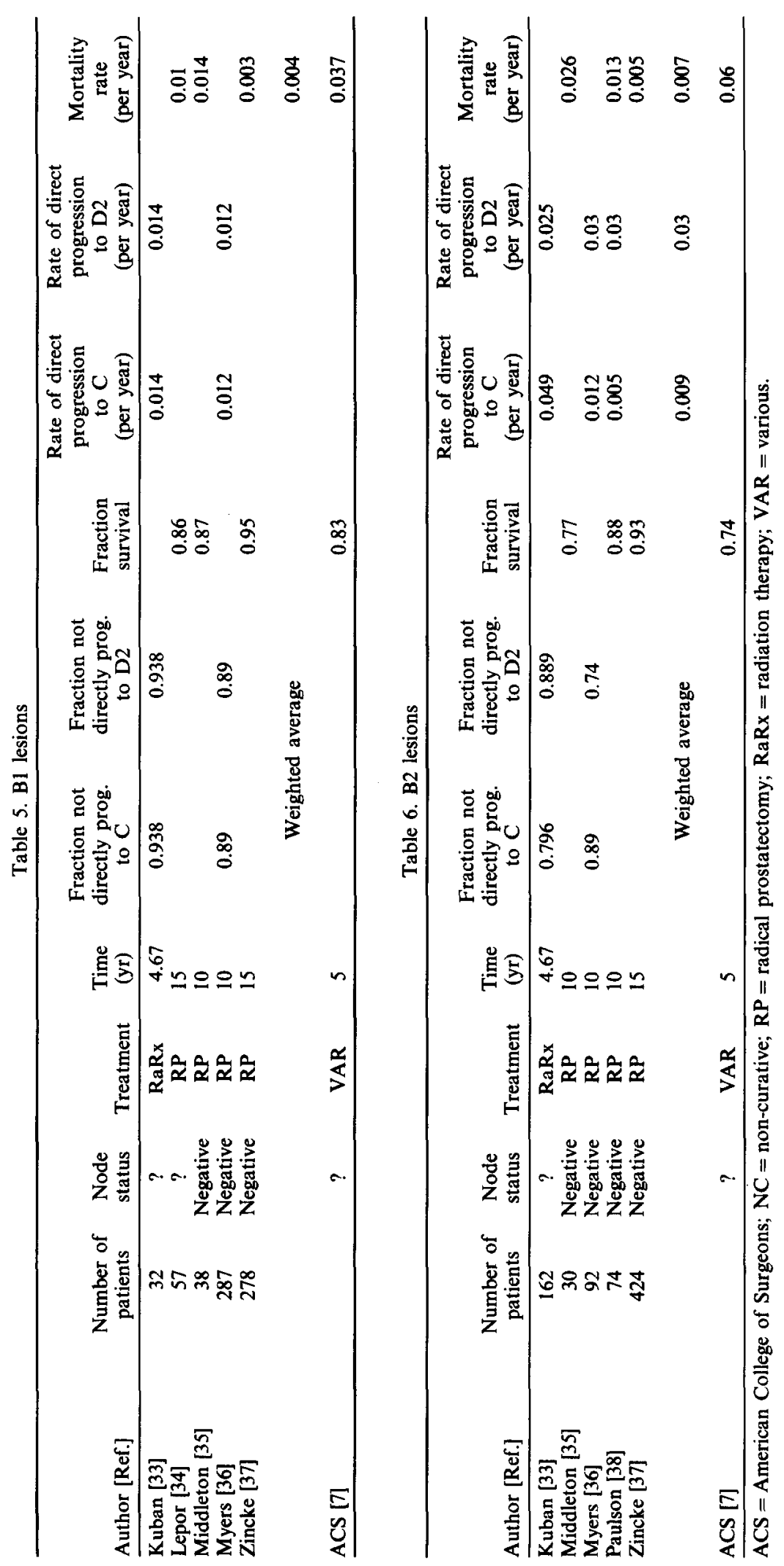




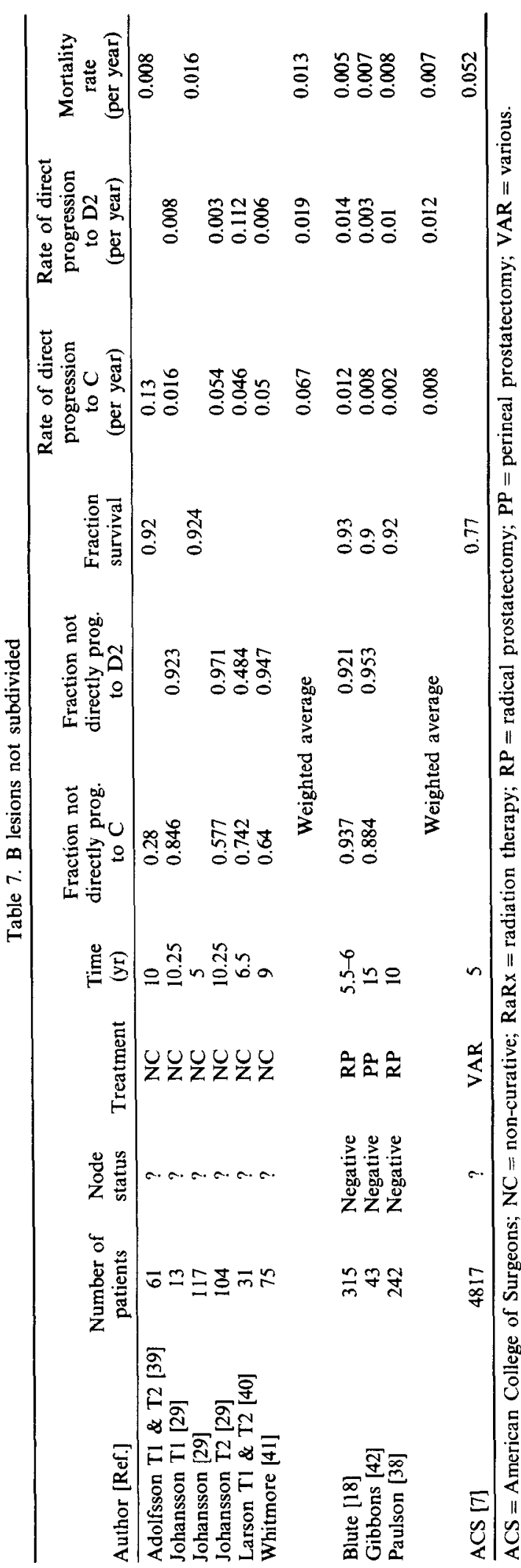

to give "best scenario" rates. In the tables, the Time column generally signifies the time until local or distant failure, but in some cases only the follow up time was reported. In order to obtain some of the data necessary to construct the tables we sought written personal communications (from Schellhammer PF, Johansson J-E, Whitmore Jr. WF, Ref. [8, 29, 41]). Not shown in the tables are the progression rate $\mathrm{Al} \rightarrow \mathrm{B}$ of 0.008 per year derived from Zhang [30]. This is compared to the Epstein study [27], where documented progression from an Al lesion to a B2 occurred in 1 of 50 patients after 8 years, while 7 of the 50 progressed to $C$ and D2 lesions over an average of 6.5 years. Assuming these passed through either an A2-or-B intermediate state, then an $\mathrm{A} 1 \rightarrow[\mathrm{A} 2]+[\mathrm{B}]$ progression rate of at least 0.026 per year is obtained. Assuming equal probability of going $\mathrm{A} 1 \longrightarrow \mathrm{A} 2$ or $\mathrm{A} 1-\rightarrow \mathrm{B}$, (see Model Assumption 5 below), this rate becomes $0.026 / 2$ or 0.013 .

\section{Model assumptions}

1. The first was to use the basic sequence of progression as described by Whitmore $[1,63]$ for pathological stages:

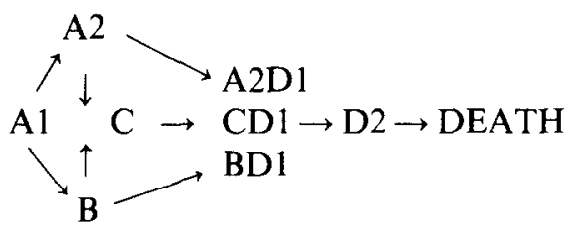

This admittedly-simplified sequence assumes a "cascade" spread of metastases [64]. Although bony metastases have been found in patients without lymph node involvement, there is a high degree of correlation between positive nodes and bony metastases [65]. To model the difference between hematogenous or lymphatic metastatic spread would have added further complexity to the model without much supportive data. The model is for pathological staging (represented as A1, A2, B, etc.), but in order to correlate these with clinical staging, we defined three stages that represented clinical A2, B and C lesions with positive lymph nodes (thus making them pathological D1): $A 2 D 1, B D I$ and $C D 1$. We assumed the major prognostic difference between clinical and pathological stages is the presence of positive lymph nodes and their impact on the overall mortality rate [59], rather than the proportion of clinical stage $A 2$ and $B$ lesions that are pathologically $C$ [11]. We considered all these D1 stages as 


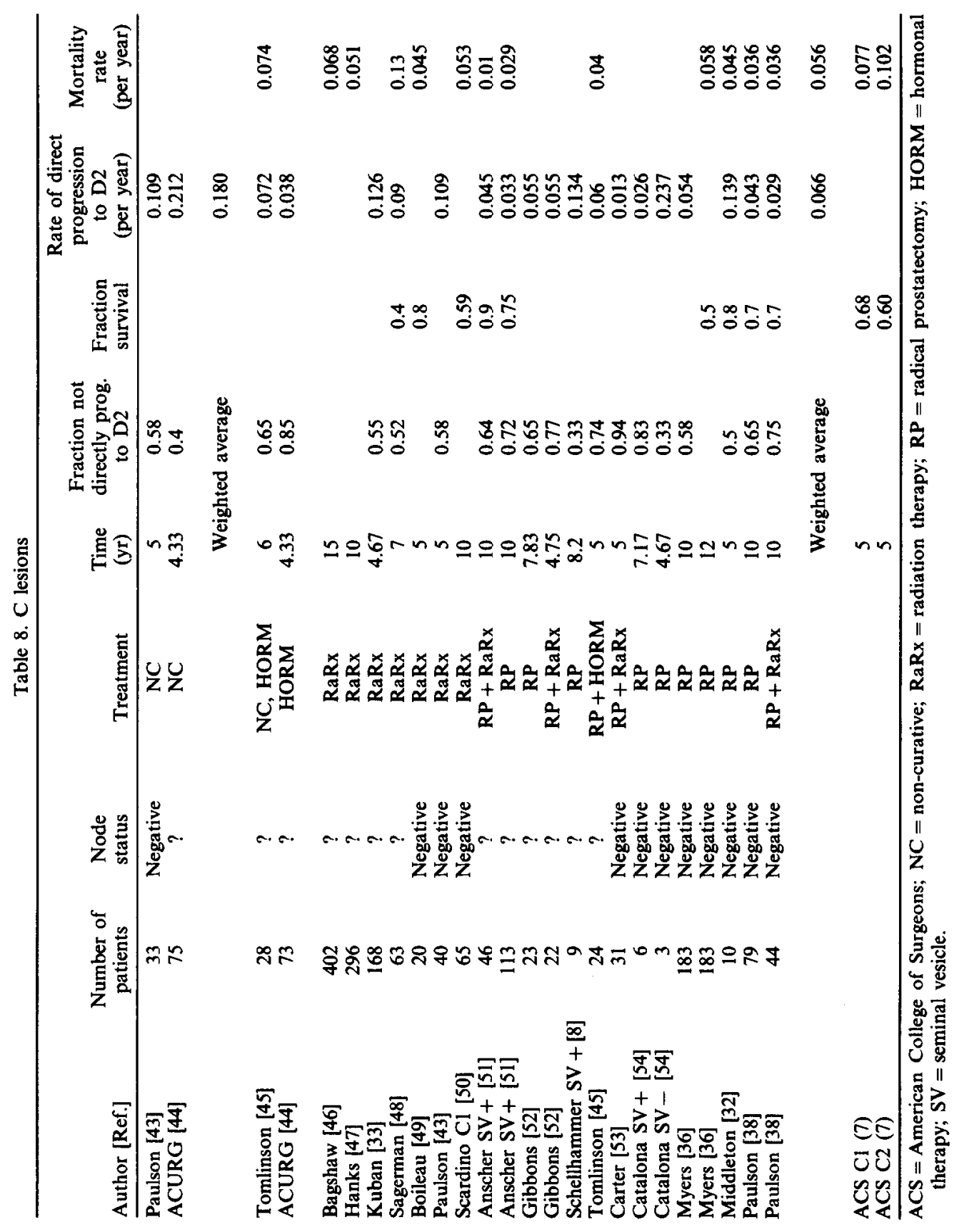




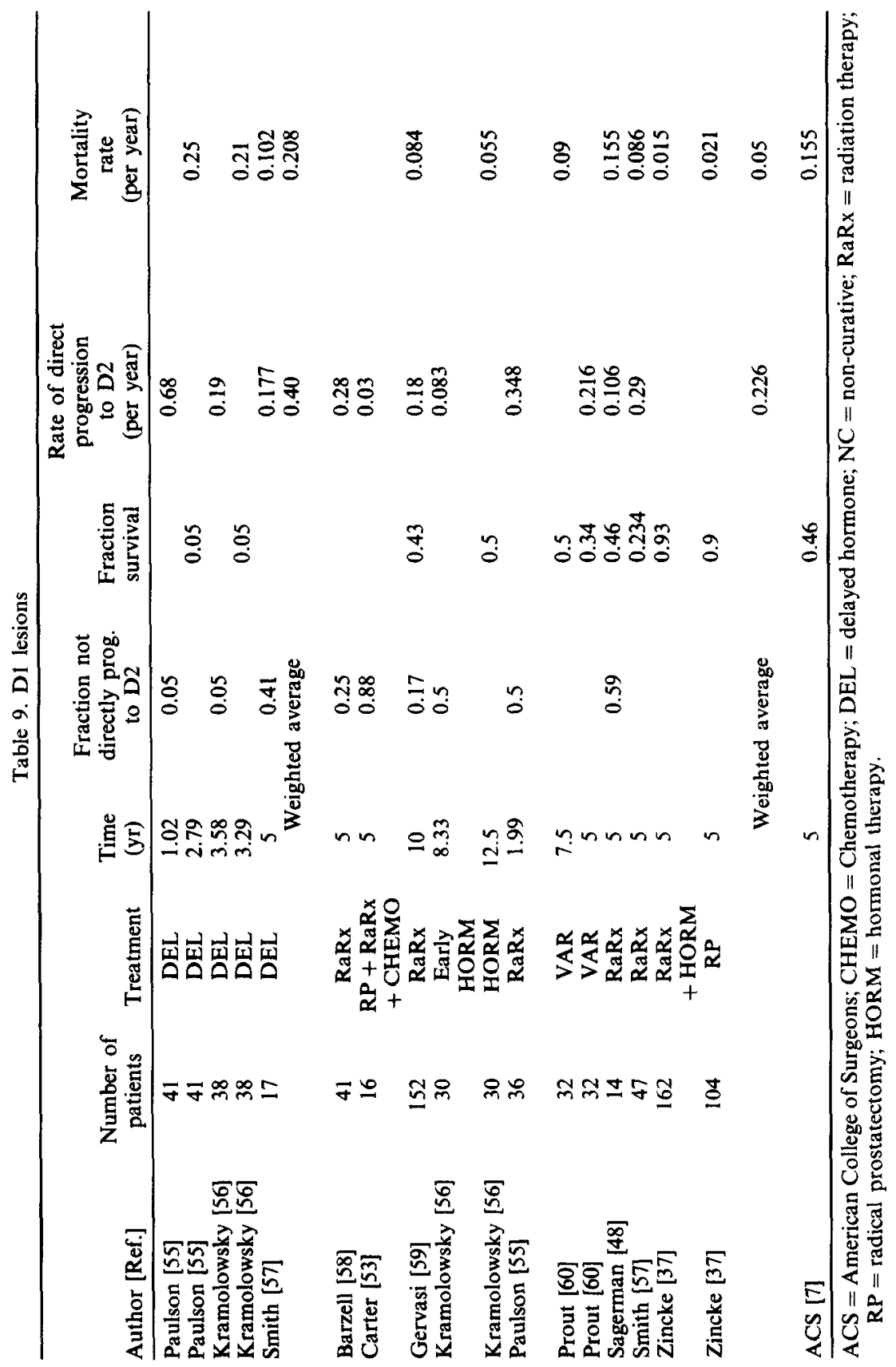


Table 10. D2 lesions

\begin{tabular}{lccccc}
\hline & $\begin{array}{c}\text { Number of } \\
\text { patients }\end{array}$ & Treatment & $\begin{array}{c}\text { Time } \\
\text { (yr) }\end{array}$ & $\begin{array}{c}\text { Fraction } \\
\text { survival }\end{array}$ & $\begin{array}{c}\text { Mortality } \\
\text { rate } \\
\text { (per year) }\end{array}$ \\
\hline Bagshaw [46] & 318 & HORM & 2 & 0.5 & 0.324 \\
Kuban [33] & 120 & HORM & 1.5 & 0.5 & 0.433 \\
Leuprolide Study Grp [61] & 101 & DES & 1 & 0.78 & 0.207 \\
Leuprolide Study Grp [61] & 98 & LEU & 1 & 0.87 & 0.104 \\
Sharifi [62] & 56 & LEU & 1.88 & 0.5 & 0.336 \\
& & Weighted average & & 0.25 \\
ACS [7] & & & 5 & 0.26 & 0.269 \\
\hline
\end{tabular}

ACS = American College of Surgeons; DES = diethylstilbestrol; LEU = leuprolide; NC = noncurative; $\mathbf{R a R x}=$ radiation therapy; $\mathbf{R P}=$ radical prostatectomy; $\mathbf{H O R M}=$ hormonal therapy.

having the same probability of progressing to D2 [16]. We did not subdivide stages B and C into B1, B2, B3, etc. because of the lack of available data. We represented this biological model in a standard Markov tree form, Fig. 1.

2. We based our model on the "expectant management" [41] of prostate cancer rather than that of the "natural history" in the purest sense. This means that given the current medical practices, that we assumed that antibiotics would be used to treat urosepsis, that palliative drainage procedures would be offered to those obstructed, and that hormones would be given to those with painful bony metastases. (Hormonal manipulation of some type has been widely used for the past 40 years [6].) Since we assumed palliative care would be given to men today, we assumed all deaths from prostate cancer would come from men with advanced D2 lesions. Although this might tend to bias results to lower-than-expected mortalities, we feel it reflects current medical practice. In the past, men died of prostate cancer without known metastases $[66,67]$, but a recent report found no deaths in a group of irradiated patients [68] when tumor recurred only locally.

3. We assumed all histological cancers are biologically active and grow and progress with time. This is debatable since there are two possible ways to explain the discrepancy between the large number of histologic adenocarcinomas and the relatively smaller number of clinically important tumors [9]. The first is that all histological cancers will eventually grow into clinically significant tumors [69], while the second assumes that all histological cancers need further transformation before becoming active [9]. In our model, we initially chose the first theory because it required fewer assumptions and estimates. We could have constructed the model by having $W E L L$ patients first enter a preliminary stage in which cancer could be diagnosed histologically but remain latent for a while before entering the A1, A2, B, etc. cascade. To do this however, would require the ability (not currently available) of knowing which autopsy cancers are clinically active [9]. Nevertheless, in order for the model to eventually yield higher cancer-specific mortality rates for blacks compared to whites, the cancer progression rates might have to be different between whites and blacks - supporting the "multi-step" theory [9]. This point will be addressed later in more detail in the Discussion.

4. We assumed stage A2 and B lesions are biologically-equivalent lesions. This is based on the similar mortality rates from the American College of Surgeons paper [7], the similar incidence of positive lymph nodes in clinical A2 and B lesions [12], morphologic data [70], and levels of prostate specific antigen in A2 and B1 lesions [71]. With this assumption, we grouped the table values for $\mathrm{A} 2$ and $\mathrm{B}$, which yielded a weighted annual transitional rate for each to $\mathrm{C}$ of 0.068 , and to $\mathrm{D} 20.028$.

5. We assumed that the progression rates per stage are the same regardless of the age of the patient although this has been debated. Some have proposed a similar prognosis regardless of age $[72,73,74]$, others have reported better corrected survival in younger patients [75], and still others have reported a poorer prognosis in the younger age groups [76].

6. We assumed the progression rates used in the model are for a homogenous group of 
the earliest lesions in a given pathological stage.

7. We assumed the autopsy prevalence of cancer is the same for blacks and whites [77].

8. We assumed no one would be spontaneously "cured" of prostate cancer.

The "gold standards"

We defined the "standards" against which to measure our model as: (1) the cancer-specific death rates from the SEER data [10], (2) the autopsy prevalence as derived by Carter [9], (3) the fraction of positive nodes per clinical stages mentioned in the Introduction [12], and (4) the annual probability of death from other causes as given in the Statistical Abstract of the United States [78]. These are obviously imperfect standards since mortality rates are based on death certificate information of lesser quality in persons of advanced age [79], and the autopsy

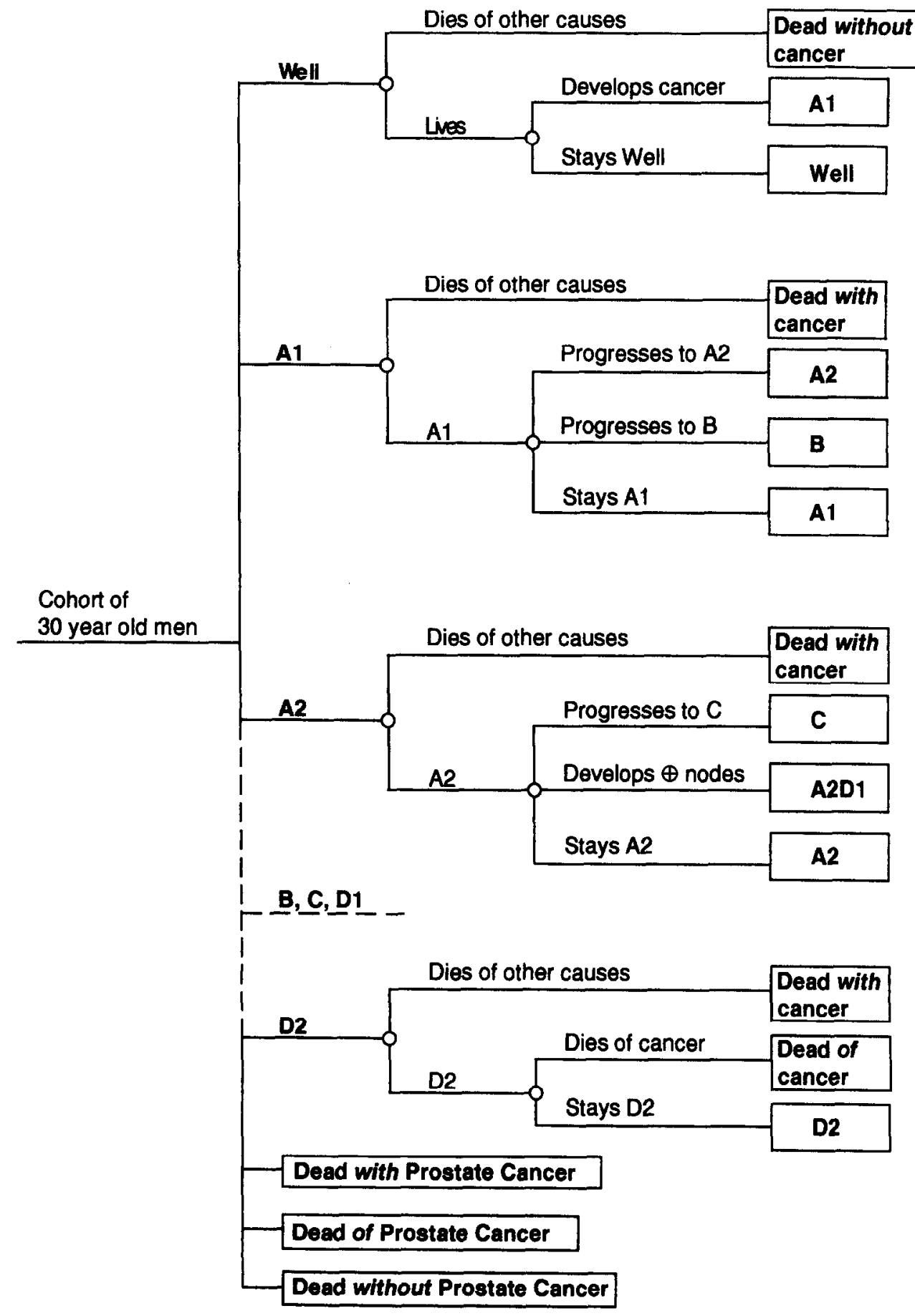

Fig. 1. Markov tree for prostate cancer progression with competing mortalities. 
prevalence rates vary in part due to technique [80]. Additionally, the range for lymph node positivity in each clinical stage is wide [12]. "Gold standards" for men older than 80 are hard to find, since data for the most elderly are usually grouped together as " $>85$ ", [78]. These flaws highlight the sources of many of the controversies surrounding prostate cancer, but we could find no better. Faced with the choice of nihilism or pragmatism, we proceeded with the development of the model.

\section{Model construction}

We constructed a Markov [4] model shown in Fig. 1 using the software Decision Maker 6.0 (Pauker SG, Sonnenberg FA, Kassirer JP, New England Medical Center, Boston MA) [81]. The categories of health or Markov states [4] are: $W E L L$ (no cancer present but other disease processes could be present), $A 1, A 2, B, C$ and so on for the stages of cancer described above and DEAD BECAUSE OF PROSTATE CANCER, DEAD WITH BUT NOT OF PROSTATE CANCER, and DEAD WITHOUT PROSTATE CANCER. In our model, a fraction of each group could progress to a more advanced stage each year, depending on the annual transitional probabilities [4]. To arrive at these, we started with the weighted averages from the tables and inserted them in subtrees of the stages where progression to death could occur without the interference of non-cancer deaths.

To model the overall public health impact of prostate cancer, we studied an imaginary cohort of 30 year old men for 50 years. Whites and blacks were studied separately because of the racial differences in mortality rates, both cancerspecific [10] and overall [78]. In the course of the following 12 months, some die of causes other than prostate cancer, some develop histological evidence of prostate cancer (and enter the $A 1$ state), but most remain in the $W E L L$ state. At the start of the second year, those in the WELL state again face the probabilities of death from other causes, of developing $A 1$ cancer, or remaining alive and free of cancer. Those who start the second year in the $A 1$ state face the probability of progressing to $A 2$ or $B$ states, or remaining alive in the $A 1$ state, or dying from other causes (with evidence of prostate cancer at autopsy). With time the WELL state gets smaller and only the $D E A D$ states get progressively larger. The various cancer states have men entering and leaving them each year.

\section{Parameters studied}

Using the model we derived mortality rates for the individual stages using the logarithmic transformation formula. When we studied competing causes of death we defined the mortality rates as the change in the number of deaths in 5 year intervals divided by the fraction alive at the end of the interval. To derive prevalence in the model we used the fraction alive with cancer at a given age divided by the total fraction still alive at that point. This gave a similar curve to the change in the number of deaths of those with cancer over a 10 year interval divided by the total number of deaths in that same period plotted against the midpoint of the interval.

\section{Statistical studies and "sensitivity index"}

To compare mortality curves generated by the model and the SEER [10] and Census Bureau [78] data, we used the software package Systat to calculate the Spearman correlation coefficients. Many sensitivity analyses [82] were performed. In order to show how much an individual parameter affected the cancer-specific mortality rates, we defined a "sensitivity index". This was derived by taking the difference in the fraction of the original cohort dead of cancer at age 75 (as determined by the parameter of concern's baseline and sensitivity analysis value), divided by the change in the parameter's baseline value and that used in the particular sensitivity analysis. This means that a parameter whose "sensitivity index" was high would affect the cancer-specific mortality more than a parameter whose sensitivity index was low.

\section{RESULTS}

(See Table 2). A set of baseline values was determined, starting with a prevalence of prostate cancer in 30 years old of 0.0005 that yielded results compatible with the "gold standards" (Figs 2 to 6). Using a value of 0.015 for the annual probability of an A1 lesion becoming an A2 lesion to 1 year in a white male $[p \mathrm{~A} 1 \mathrm{~A} 2(\mathrm{w})]$, the Spearman correlation coefficient with the SEER [10] white mortality rates was 0.9812 (for ages $35-80$ ). The Spearman correlation coefficient was 1.000 for the overall mortality rate of the model and the Census Bureau [78] data, the model's prevalence and the Carter [9] data, and for the SEER black mortality rates and the model [using $p \mathrm{~A} 1 \mathrm{~A} 2$ (b) of 0.03 ]. For ages $50-80$, the average fractions of positive lymph nodes in clinical stages A2, B, 


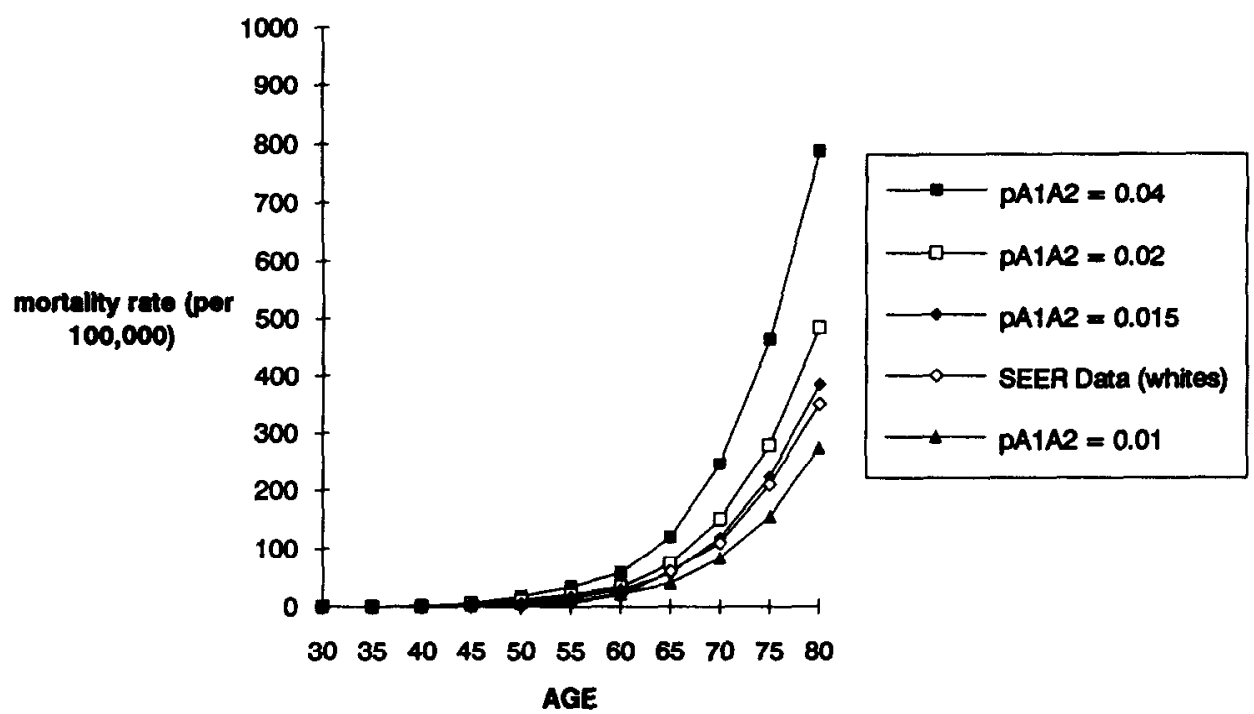

Fig. 2. Results of sensitivity analysis varying the annual probability of progression of an A1 lesion to an A2 lesion (or to a B lesion) for whites (abbreviated as $p$ A1A2). SEER Data from Ref. [10].

and $C$ were $0.18,0.18$ and 0.40 respectively, comparable to that reported by Donohue [12]. Using the baseline values in the model the following average distribution of pathologically-staged cancer for blacks $50-80$ years old were obtained: A1 0.72; A2 0.08; B 0.08; C 0.03 , D1 0.05 ; and D2 0.05 . This meant that blacks had on the average, proportionately more advanced lesions compared to whites, whose derived distribution of lesions were: $\mathrm{A} 1 \mathrm{0.79} ; \mathrm{A} 2$ 0.06 ; B 0.06; C 0.02; D1 0.04; and D2 0.03. For both races, older men had a larger proportion of more advanced lesions compared to younger men.
A large number of sensitivity analyses were done for the cohort analysis as well as for the individual stages (Table 2, Figs 2 to 5). Not surprisingly, the incidences of cancer in the younger years had the highest sensitivity indices and so greatly affected the cancer-specific mortality rates. The annual probability of an Al lesion progressing to an $A 2$ (or $B$ ) lesion in the following year ( $p \mathrm{~A} 1 \mathrm{~A} 2$ and $p \mathrm{~A} 1 \mathrm{~B})$ also had an important effect. However, the progression rates from $\mathrm{A} 2, \mathrm{~B}$, and $\mathrm{D} 2$ lesions $(p \mathrm{~A} 2 \mathrm{C}, p \mathrm{BC}$, $p \mathrm{~A} 2 \mathrm{D} 1, p \mathrm{BD} 1, p \mathrm{DIE})$ had smaller effects. The smallest sensitivity indices were for the transitional probabilities of progression from $C$ and

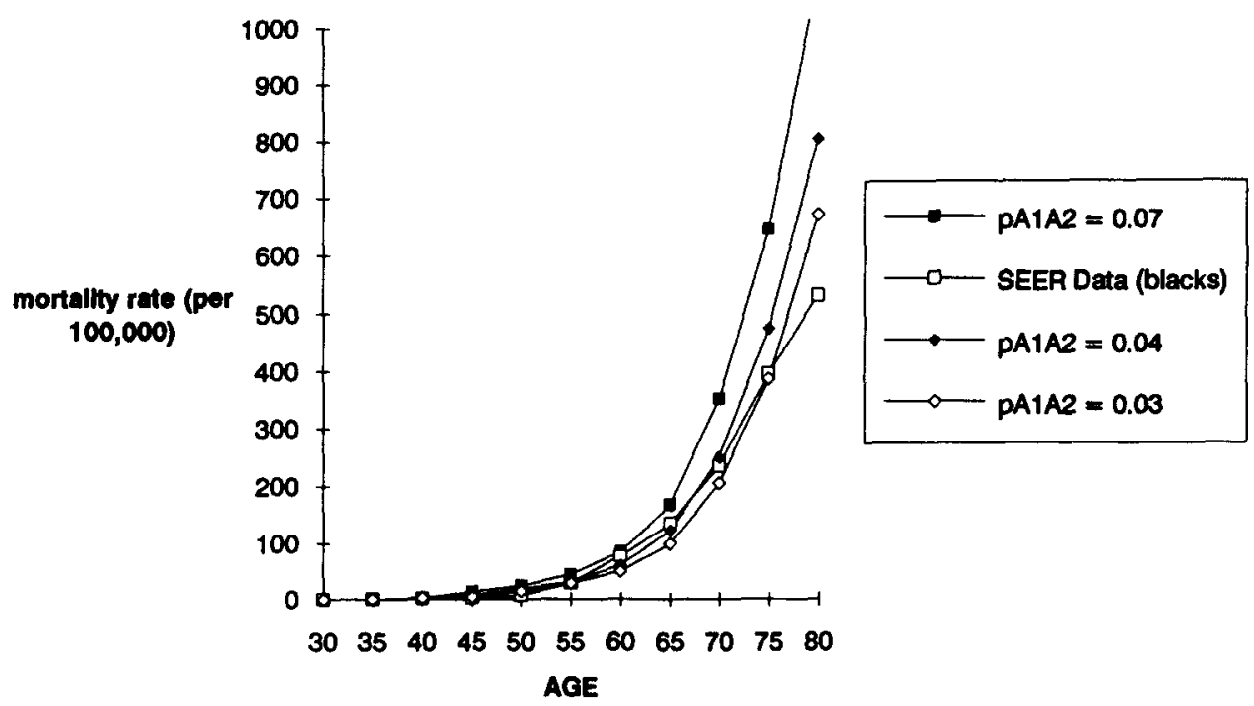

Fig. 3. Results of sensitivity analysis varying the annual probability of progression of an Al lesion to an A2 lesion (or to a B lesion) for blacks (abbreviated as pA1A2). SEER data from Ref. [10]. 


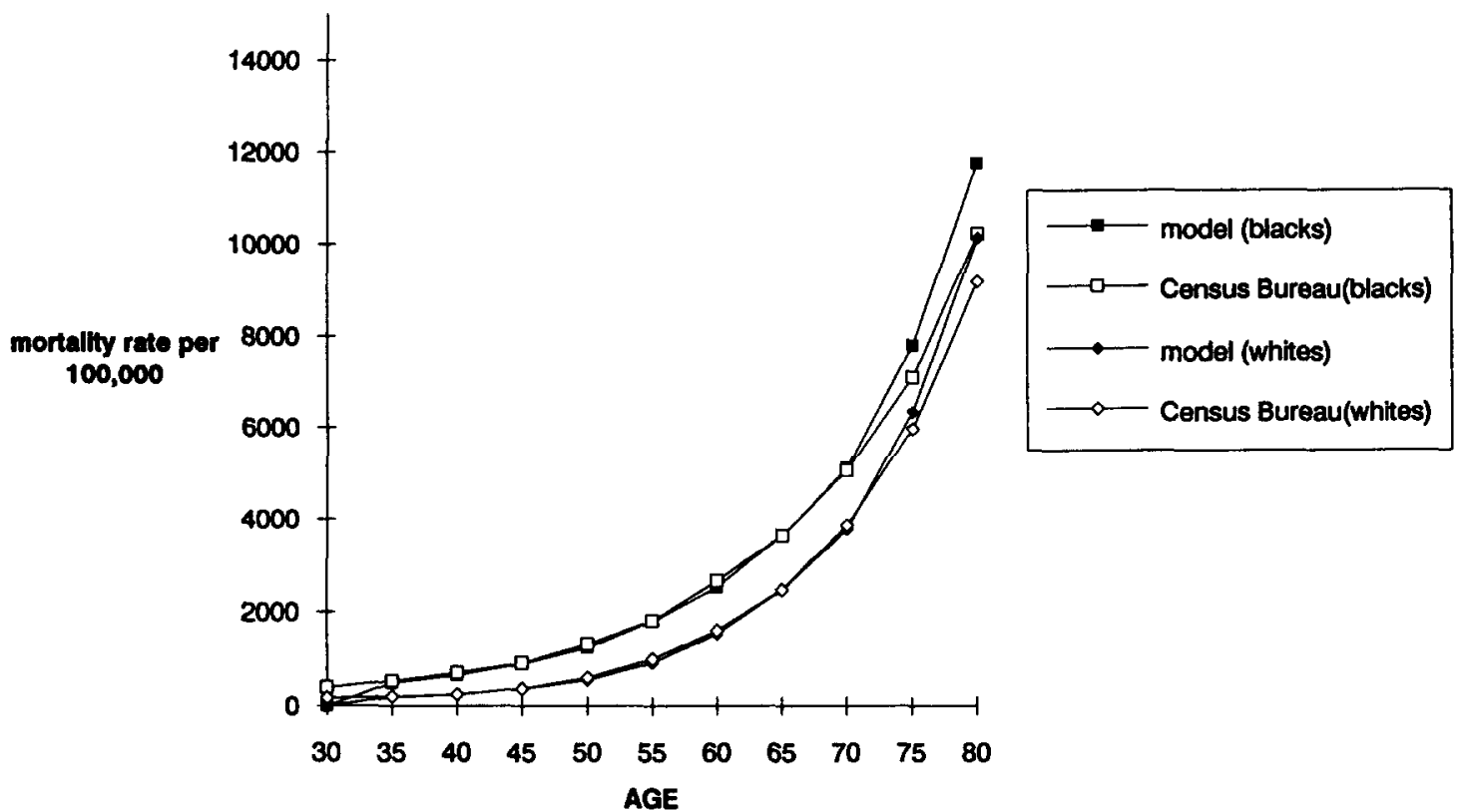

Fig. 4. Mortality rates (all causes) per age for blacks and whites. Census Bureau Data from Ref. [78]. The model used baseline transitional probabilities from Table 2 . For whites the value of $p \mathrm{~A} 1 \mathrm{~A} 2(\mathrm{w})$ and $p \mathrm{~A} 1 \mathrm{~B}(\mathrm{w})$ was 0.02 ; for blacks $p \mathrm{~A} 1 \mathrm{~A} 2(\mathrm{~b})$ and $p \mathrm{~A} 1 \mathrm{~B}(\mathrm{~b})$ was 0.03 .

D1 lesions ( $p \mathrm{CD} 1, p \mathrm{D} 1 \mathrm{D} 2)$, meaning these parameters affect cancer-specific mortality of the population only slightly. Figure 5 displays the effects on the cancer-specific mortality when different incidence values were used in the model. Generally speaking, if no additional cases of histological prostate cancer were to develop beyond a certain age, the cancer-specific mortality would not change until 5-10 years afterwards.

\section{DISCUSSION}

Our model yielded mortality rates consistent with the SEER [10] and Census Bureau [78] data, differentiated the large number of patients dying with prostate cancer as opposed to those dying of cancer, and gave literature-consistent fractions of lymph node positivity in clinical stages A2, B and C [12]. Additionally our model showed a larger proportion of advanced lesions in blacks compared to whites, and in older

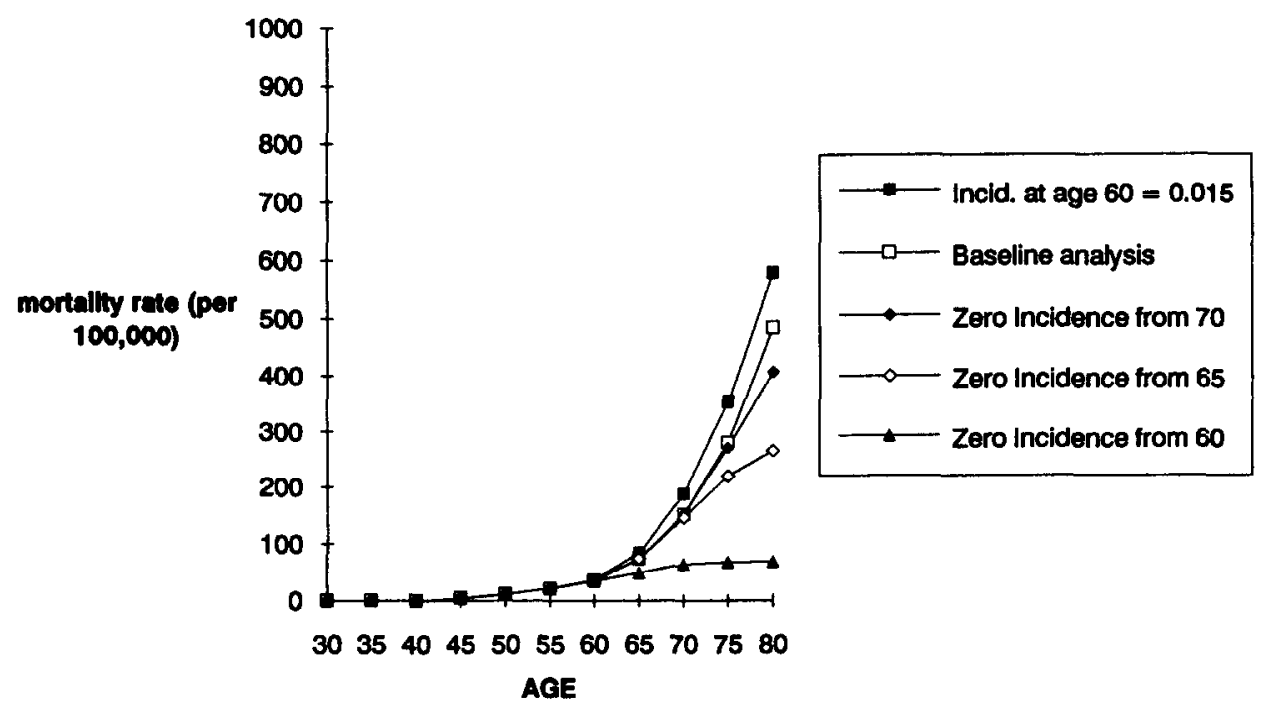

Fig. 5. Sensitivity analyses showing the effects on the annual prostate cancer-specific mortality rates (whites) when using different values for the pathological incidences of cancer at given ages. "Zero Incidence" means setting to zero, the number of new cases of prostate cancer after the indicated age. 


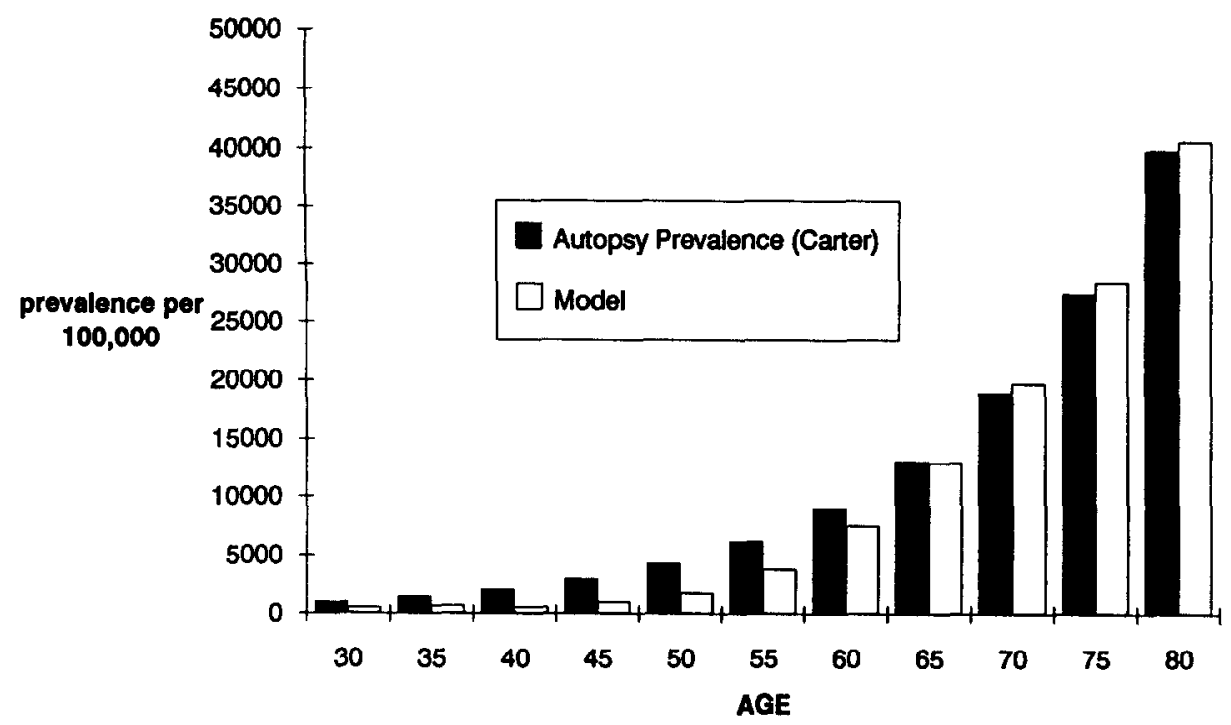

Fig. 6. The pathologic prevalence of prostate cancer per 100,000 black males at a given age. The literature values were derived from Carter [9]. The prevalences for whites as derived from the model were similar.

compared to younger men $[60,77]$. We will discuss the implications of this model but will first point out the potential weaknesses of this paper.

The assumptions and reasoning are clearly stated and can be supported or criticized directly [82]. We made use of the clinical literature with all its flaws, so the transitional probabilities are certainly open to question. The literature gives widely-varying rates for most of the clinical stages. These can be explained by the problems mentioned in the introduction as well as: broad confidence limits even within a single paper (for example [29]), some selection bias (e.g. the predominance of well-differentiated tumors in Johansson's series $[6,29]$ and the entry criteria for Whitmore's series [41, 83]). Our calculations could also be flawed due to difficulties translating data into specific fractions of "not becoming C", "not becoming D2", and the time frame of these events. Our response to these criticisms is that our baseline numbers taken together yield results compatible to those standards--also flawed-available. Yet the sensitivity analyses showed that when competing causes of death are considered, a wide range of values for most of the parameters used in the model will yield similar cancer-specific mortality. This suggests that debate in areas concerning these low-sensitivity parameters, for example the best means of treating a $\mathrm{C}$ lesion, will have less of an effect on the male population's cancer-specific mortality. This is not the case however with those parameters with the higher sensitivity indices: the pathological inci- dences in younger men, and the progression probability of A1 lesions as a group ( $p \mathrm{~A} 1 \mathrm{~A} 2$ and $p$ A1B). These parameters greatly impact the cancer-specific mortality and do deserve further study and debate.

Since the pathologic incidences are so sensitive, a potential criticism of this model is its use of primarily one paper [9] for the derivation of the pathologic prevalences and incidences. Certainly there is a wide range of values reported for these, as shown by Stamey [80]. We used the Carter paper [9] because it was a compilation of 5250 autopsies from several papers concerning the population studied in our model-males in the United States-from which a smoothed curve of prevalence per age group was constructed. We felt this derived curve gave us information not found in other autopsy series: a means to minimize the effects of small sample sizes and variations in pathologic technique [80], as well as to project cancer prevalence in the younger age groups subject to statistical error [76]. The Carter paper was therefore useful for a model such as ours whose objective was to define those parameters with the largest impact (i.e. highest sensitivity indices) on prostate cancer-specific mortality rates. However, caution is needed when using these values for determination of public policy due to their extreme sensitivity. Practically speaking, we urge future and more precise autopsy data, which may well decide the appropriateness of mass screening. An additional practical insight from the model is the demonstration of the lag time between changing an incidence value and the resulting 
projected effect on the cancer-specific mortality rates as shown in Fig. 5. Although the focus of this paper was not on when or whether prostate cancer should be screened, one can see that it may take 5-10 years to see a favorable reduction in the cancer-specific mortality.

Likewise, whether or not to screen will in large part also depend on another highly sensitive value: how quickly Al lesions (taken as a group ) progress. The current published series of Al lesions show a wide range in progression rates, Table 3 . There are undoubtedly different subsets at higher or lower risk for progression [84] which are important to identify in order to make the best decisions for an individual patient. Yet for the purpose of an epidemiological model such as ours, indeed for the purpose of screening the male population as a whole, we must know the progression probability of Al lesions considered as a group. The question then becomes: how representative are the Table 3 series to all patients with A1 cancer? Since we cannot know this for certain from the literature, we can use the model's sensitivity analyses to define reasonable upper and lower values for Al progression rates, to project what the eventual cancer-specific mortality would be if a given rate is assumed. For example, a value of 0.01 seems too low for the annual probability of progression of an untreated A1 to an A2 lesion in whites $[p \mathrm{~A} 1 \mathrm{~A} 2(w)]$, since when used in our model, the projected cancer-specific mortality rates were lower than the SEER data. (We would anticipate an untreated group of A1 lesions would progress and ultimately yield higher cancer-specific mortality rates than the SEER which included treated patients.) In order to approximate the mortality rates in the SEER data, a $p$ A1A2(w) value of 0.015 is needed - but this would be a feasible value only if the treatment given to SEER patients had no effect. So values of 0.01 and 0.15 might be too low for what the "natural history" or "expectant management" of a group of A1 lesions would be assuming treatment has a beneficial effect. To set a reasonable "upper limit", we used a $p \mathrm{~A} 1 \mathrm{~A} 2(\mathrm{w})$ of 0.04 -which resulted in projected cancer-specific mortality rates twice that of SEER. This would be possible only if the treatment given to the SEER patients were $100 \%$ efficacious for one-half of all lesions. This is unlikely given that in the SEER data, $60-65 \%$ of the lesions were considered "localized" at the time of diagnosis [85] and in the ACS paper, only about one-half of patients were in clinical
A and B stages at the time of diagnosis [7]. In fact many of these are probably pathological D1 lesions [12] less amenable to cure. We therefore chose an "in-between" value of 0.02 for the pA1A2 in our baseline analysis for white men. This value seems plausible, yet leaves room for the possible effects of treatment.

Yet this value did not seem as appropriate for the African-American cohort. When we used 0.02 for the annual probability of progression of $\mathrm{A} 1$ to $\mathrm{A} 2$ lesions in blacks [ $p \mathrm{~A} 1 \mathrm{~A} 2(\mathrm{~b})]$, we obtained cancer-specific mortality rates lower than the SEER data (Fig. 3). As can be seen in the graph, we needed to use higher values for $p \mathrm{~A} 1 \mathrm{~A} 2(\mathrm{~b})$ and $p \mathrm{~A} 1 \mathrm{~B}(\mathrm{~b})$ to yield the appropriate increase in cancer-specific mortality rates compared to whites. This occurred even if we kept the progression rates for the remaining stages in our model the same as in whites, (consistent with the findings of Austin et al. [86] but different from the ACS study [87] where black patients in clinical stages $B, C$, and D fared worse). The fact that we had to use a different $p \mathrm{~A} 1 \mathrm{~A} 2$ value for whites and blacks in order to match the appropriate SEER curves, suggests that perhaps pathological Al lesions behave differently in the two races. This would support the theory that prostate cancer requires multiple steps in order to achieve biological activity $[9,77,88]$, although access to care may also play a role [88]. Our model is therefore useful to define "ballpark" ranges for feasible Al progression rates for the purpose of epidemiological projections. However we must again caution that these values seem appropriate when used together with our set of baseline incidences. If the model's pathological incidences are in fact erroneously low, then our "ballpark" values for A1 progression would tend to be erroneously high. Nevertheless we believe the model is useful since it uses numbers compatible with those found in the literature, and rank orders the many parameters to show their relative impact on cancer-specific mortality.

Although our model has some potential applications, it also has some potential misapplications. The progression rates used in this model should not be used to predict the prognosis of individual patients, since tumor volume or grade which can be helpful in predicting progression [84], were not explicitly modeled. Our model could be made more complex to involve these subsets within the stages, but for this to occur, both the proportion of these subsets and their progression rates would need to be known. 
Therefore the baseline transitional probabilities should not be used in the future as "historical controls" against which to measure the efficacy of a particular treatment. One might be tempted at this point to discuss further the implications of the sensitivity indices in Table 2, such as the relative value of current therapies. However, we do not feel we should do this until the model is expanded to include quality of life adjustments [82] and cost issues. Although unfortunately we cannot yet answer many practical questions about screening and treatment for prostate cancer, we do not want to minimize this model's utility since it correlates the clinical literature with its epidemiological consequences in an explicit fashion [82]. Without such a correlation, the full public health consequences of various test/treatment strategies cannot be quantified if the only endpoint is a theoretical "Quality Adjusted Life Year", rather than the more practical "cancer-specific" and "overall" mortality rates.

In summary, this model correlates the clinical literature with the epidemiology of prostate cancer and can be used for further decision analyses. We recommend that future research be done to more precisely quantify the pathological incidence of prostate cancer in men under 50-60 years of age. More certainty is also needed before generalizing the results of relatively small Al series to millions of men, since Al progression rates critically affect the eventual cancer-specific mortality. Enough uncertainty remains at this point however, that we cannot advocate widespread screening for prostate cancer until its merit be demonstrated either by the definitive long term study, or by examination of costs and quality-of-life-adjusted benefits.

Acknowledgements - The authors would like to thank David R. Scrase MD for his encouragement throughout the project. We are also grateful for the secretarial support of Kamala Cummings, Angie Rcinking, and Brenda Wisneski.

\section{REFERENCES}

1. Whitmore WF. Background for screening: natural history and treatment. EORTC Genitourinary Group Monograph 5: Progress and Controversies in Oncological Urology Il. New York: Alan R. Liss, Inc.; 1988: 123-130.

2. Optenberg SA, Thompson IM. Economics of screening for carcinoma of the prostate. Urol Clin N Am 1990; 17: 719-737.

3. Boring CC, Squires TS, Tong T. Cancer statistics 1991. CA 1991; 41: 19-36.

4. Beck JR, Pauker SG. The Markov process in medical prognosis. Med Decis Making 1983; 3: 419-458.
5. Grayhack JT, Assimos DG. Prognostic significance of tumor grade and stage in the patient with carcinoma of the prostate. Prostate 1983; 4: 13-31.

6. Scardino PT. Early detection of prostate cancer. Urol Clin N Am 1989; 16: 625-655.

7. Schmidt JD, Mettlin CJ, Natarajan $\mathrm{N}$ et al. Trends in patterns of care for prostatic cancer 1974-1983: results of surveys by the American College of Surgeons. J Urol 1986; 135: 416-421.

8. Schellhammer PF. Radical prostatectomy patterns of local failure and survival in 67 patients. Urol 1988; 31 : 191-197.

9. Carter HB, Piantadosi S, Isaacs JT. Clinical evidence for and implications of the multistep development of prostate cancer. J Urol 1990; 143: 742-746.

10. Young JC, Percy CL, Asire AA et al. Cancer incidence and mortality in the United States, 1973-1977. Nat Cancer Inst Monogr 1981; No. 57.

11. Catalona WJ, Stein AJ. Staging errors in clinically localized prostatic cancer. J Urol 1982; 127: 452-456.

12. Donohue RE, Mani JC, Whitesel JA, Mohr S et al. Pelvic lymph node dissection. Urol 1982; 20: 559-656.

13. Freiha FS, McNeal JE, Stamey TA. Selection criteria for radical prostatectomy based on morphometric studies in prostate carcinoma. Natl Cancer Inst Monogr 1988; No. 7: 107-108.

14. Montie JE. Significance and treatment of positive margins or seminal vesicle invasion after radical prostatectomy. Urol Clin N Am 1990; 17: 803-812.

15. Myers RP, Fleming TR. Course of localized adenocarcinoma of the prostate treated by radical prostatectomy. Prostate 1983; 4: 461-472.

16. Brawn P, Kuhl D, Johnson III C et al. Stage DI prostate carcinoma. Cancer 1990; 65: 538-543.

17. Perez CA, Fair WR, Ihde D. Carcinoma of the prostate. In: DeVita VT, Hellman S, Rosenberg SA, Eds. Cancer: Principles and Practice of Oncology. Philadelphia, PA: JC Lippincott; 1989: 1023-1058.

18. Blute ML, Nativ O, Zincke H, Farrow GM, Therneau T, Lieber MM. Patterns of failure after radical retropubic prostatectomy for clinically and pathologically localized adenocarcinoma of the prostate: influence of tumor deoxyribonucleic acid ploidy. J Urol 1989; 142: $1262-1265$.

19. Cantrell BB, DeKlerk DP, Eggleston JC, Boitnott JK, Walsh PC. Pathological factors that influence prognosis in Stage A prostatic cancer: the influence of extent versus grade. J Urol 1981; 125: 516-520.

20. George NJR. National history of localized prostatic cancer managed by conservative therapy alone. Lancet 1988; 494-497.

21. Moskovitz B, Nitecki S, Richter Levin D. Cancer of the prostate: Is there a need for aggressive treatment? Urol Int 1987; 42: 49-52.

22. Handley R, Carr TW, Travis D et al. Deferred treatment for prostate cancer. Br J Urol 1988; 62: $249-253$

23. Thompson IM, Zeidman EJ. Extended follow-up of Stage Al carcinoma of prostate. Urol 1989; 33: 455-458.

24. Beck JR, Pauker SG, Gottlieb JE, Klein K, Kassirer JP. A convenient approximation of life expectancy (The “DEALE”). Am J Med 1982; 73: 889-897.

25. Roach PJ, Fleming C, Hagen MD, Pauker SG. Prostatic cancer in a patient with asymptomatic HIV infection. Med Decis Making 1988; 8: 132-144.

26. Blute ML, Zincke H, Farrow GM. Long-term followup of young patients with Stage A adenocarcinoma of the prostate. J Urol 1986; 136: 840-943.

27. Epstein JI, Paull G, Eggleston JC, Walsh PC. Prognosis of untreated Stage Al prostatic carcinoma: a study of 94 cases with extended follow-up. J Urol 1986; 136: $837-839$. 
28. Haapiainen R. Latent (pTO) prostatic carcinoma-a retrospective study of frequency and natural history. Ann Chlr Gynaecol 1986; 75: 172-176.

29a. Johansson J-E, Andersson S, Krusemo U, Adami H, Bergstrom R, Kraaz W. Natural history of localized prostatic cancer. Lancet $1989 ; 799-803$.

29b. Johansson J-E, Adami H, Anderson S, Bergstrom R, Holmberg L, Krusemo UB. High 10-year survival rate in patients with early, untreated prostatic cancer. JAMA 1992; 267: 2191-2196.

30. Zhang G, Wasserman NF, Sidi AA, Reinberg $Y$, Reddy PK. Long-term follow-up results after expectant management of Stage Al prostatic cancer. J Urol 1991; 146: 99-103.

31. Lowe BA, Listrom MB. Management of Stage A prostate cancer with a high probability of progression. J Urol 1988; 140: 1345-1347. (See also reply of authors J Urol 1989; 142: 832.)

32. Middleton RG, Smith JA, Melzer RM, Hamilton PE. Patient survival and local recurrence rate following radical prostatectomy for prostatic carcinoma. J Urol 1986; 136: 422-424.

33. Kuban DA, El-Mahdi AM, Schellhammer PF. Prognosis in patients with local recurrence after definitive irradiation for prostatic carcinoma. Cancer 1989; 63: 2421-2425.

34. Lepor $\mathbf{H}$, Walsh PC. Long-term results of radical prostatectomy in clinically localized prostate cancer. National Institutes of Health. Consensus Development Conference on the Management of Clinically Localized Prostate Cancer. Natl Cancer Inst Monogr 1988; No. 7: 117-122.

35. Middleton RG, Larsen RH. Selection of patients with Stage B prostate cancer for radical prostatectomy. Urol Clin North Am 1990; 17: 779-785.

36. Myers RP, Fleming TR. Course of localized adenocarcinoma of the prostate treated by radical prostatectomy. Prostate 1983; 4: 461-472.

37. Zincke $\mathbf{H}$. Extended experience with surgical treatment of Stage D1 adenocarcinoma of prostate. Urol (Suppl.) 1989; 23(5): 27-36.

38. Paulson D, Moul JW, Walther PJ. Radical prostatec tomy for clinical Stage T1-2NOMO prostatic adenocarcinoma: long-term results. J Urol 1990; 144 $1180-1184$.

39. Adolfsson J, Carstensen J. Natural course of clinically localized prostate adenocarcinoma in men less than 70 years old. J Urol 1991; 146: 96-98.

40. Larson A, Norlen BJ. Five-year follow-up of patients with localized prostatic carcinoma initially referred for expectant treatment. Scand J Urol Nephr Suppl 93 1985; 48: 30 .

41. Whitmore WF, Warner JA. Thompson IM. Expectant management of localized prostatic cancer. Cancer 1991; 67: 1091-1096.

42. Gibbons RP, Correa RJ, Brannen GE, Weissman RM. Total prostatectomy for clinically localized prostatic cancer: long-term results. J Urol 1989; 141 : 564-566.

43. Paulson DF, Hodge GB, Hinshaw W, The Uro-Oncology Research Group. Radiation therapy versus delayed androgen deprivation for Stage $\mathrm{C}$ carcinoma of the prostate. J Urol 1984; 131: 901-902.

44. Byar DP. The Veterans Administration Cooperative Urological Research Group's studies of cancer of prostate. Cancer 1973; 32: 1126-1130.

45. Tomlinson RL, Currie DP, Boyce WH. Radical prostatectomy: palliation for Stage C carcinoma of the prostate. J Urol 1977; 11: 85-87.

46. Bagshaw MA. Potential for radiotherapy alone in prostate cancer. Cancer 1985; 55: 2079-2085.

47. Hanks GE. External-beam radiation therapy for clinically localized prostate cancer: patterns of care studies in the United States. Natl Cancer Inst Monogr 1988; 7 : $75-84$.

48. Sagerman RH, Chun HC, King GA, Chung CT, Dalal PS. External beam radiotherapy for carcinoma of the prostate. Cancer 1989; 63: 2468-2474.

49. Boileau MA, Dowling RA, Gonzales M, Handel PH, Benson GS, Corriere JN. Interstitial gold and external beam irradiation for prostate cancer. J Urol 1988; 1399: 985-988.

50. Scardino RT. Is radiotherapy effective for locally advanced (stage $\mathrm{C}$ or T3) prostate cancer? In: Murphy GP, Khoury S, Eds. Therapeutic Progress in Urological Cancers. New York: Alan R. Liss; 1989: 223-239.

51. Anscher MS, Prosnitz LR. Postoperative radiotherapy for patients with carcinoma of the prostate undergoing radical prostatectomy with positive surgical margins, seminal vesicle involvement and/or penetration through the capsule. J Urol 1987; 138: 1407-1412.

52. Gibbons RP, Cople BD, Richardson RG et al. Adjuvant radiotherapy following radical prostatectomy: results and complications. J Urol 1986; 135: $65-68$.

53. Carter GE, Lieskovsky G, Skinner DG, Petrovich Z. Results of local and/or systemic adjuvant therapy in the management of pathological stage $\mathrm{C}$ or D1 prostate cancer following radical prostatectomy. J Urol 1989; 42: 1266

54. Catalona WJ, Miller DR, Kavoussi LR. Intermediateterm survival results in clinically understaged prostate cancer patients following radical prostatectomy. J Urol 1988; 140: 540-543.

55. Paulson DF, Cline WA, Koefoot RB, Hinshaw W, Stephani S, Uro-Oncology Research Group. Extended field radiation therapy versus delayed hormonal therapy in node positive prostatic adenocarcinoma. J Urol 1982; 127: 935-937.

56. Kramolowsky EV. The value of testosterone deprivation in Stage D1 carcinoma of the prostate. J Urol 1988; 139: 1242-1244.

57. Smith JA, Haynes TH, Middleton RG. Impact of external irradiation on local symptoms and survival free of disease in patients with pelvic lymph node metastasis from adenocarcinoma of the prostate. J Urol 1984; 131: 705-707.

58. Barzell W, Bean MA, Hilaris BD, Whitmore WF. Prostatic adenocarcinoma: relationship of grade and local extent to the pattern of metastates. J Urol 1977; 11: 278-282.

59. Gervasi LA, Mata J, Easley JD et al. Prognostic significance of lymph nodal metastases in prostate cancer. J Urol 1989; 142: 332-336.

60. Prout GR, Heaney JC, Griffin PP, Daly JJ, Shipley WU. Nodal involvement as a prognostic indicator in patients with prostatic carcinoma. J Urol 1980; 124: 226-231.

61. Leuprolide Study Group. Leuprolide versus diethylstilbestrol for metastic prostate cancer. $\mathbf{N}$ Engl $\mathbf{J}$ Med 1984; 311: 1281-1286.

62. Sharifi R, Soloway M, The Leuprolide Study Group. Clinical study of leuprolide depot formulation in the treatment of advance prostate cancer. J Urol 1990; 143: 68-71.

63. Whitmore WF Jr. Natural history of low-stage prostatic cancer and the impact of early detection. Urol Clin N Am 1990; 17: 689-697.

64. Viadana E, Bross IDJ, Pickren JW. The metastatic spread of kidney and prostate cancers in man. Neoplasma 1976; 23: 323-332.

65. Varkarakis MJ, Murphy GP, Nelson CMK, Chehval M, Moore RH, Flocks HR. Lymph node involvement in prostatic carcinoma. Urol Clin N Am 1975; 2: 197-212. 
66. Arnheim FK. Carcinoma of the prostate: a study of the postmortem findings in one hundred and seventysix cases. J Urol 1948; 60: 559-603.

67. Schoonees R, Palma LD, Gaeta JF et al. Prostatic carcinoma treated at categorical center. NY St J Med 1972; 1021-1027.

68. Kuban DA, El-Mahdi AM, Schellhammer PD. Mortality in prostatic carcinoma. Urol 1989; 33: $1-5$.

69. McNeal JE. Origin and development of carcinoma in the prostate. Cancer 1969; 23: 24-34.

70. McNeal JE, Price HM, Redwine EA et al. Stage A versus Stage B adenocarcinoma of the prostate. Morphological comparison and jiological significance. J Urol 1988; 139: 61-65.

71. Stamey TA, Kabalin JN, McNeal JE et al. Prostate specific antigen in the diagnosis and treatment of adenocarcinoma of the prostate. II. Radical prostatectomy treated patients. J Urol 1989; 141: 1076-1983.

72. Johansson JE, Andersson S-O. Deferred treatment in localized prostatic cancer. Acta Oncol 1991; 30: 221-223.

73. Harrison GSM. The prognosis of prostatic cancer in the younger man. Br J Urol 1983; 55: 315-320.

74. Smedley HM, Sinnott M, Freedman LS, Macaskill P et al. Age and survival in prostatic carcinoma. $\mathbf{B r} \mathbf{J}$ Urol 1983; 55: 529-533.

75. Norlen BJ. Survival and mortality in prostatic cancer. Acta Oncol 1991; 30: 141-144.

76. Wilson JM, Kemp IW, Stein GJ. Cancer of the prostate. Do younger men have a poorer survival rate? Br J Urol 1984; 56: 391-396.
77. Dhom G. Epidemiologic aspects of latent and clinically manifest carcinoma of the prostate. J Cancer Res Clin Oncol 1983; 106: 210-218.

78. U.S. Bureau of the Census, Statistical Abstract of the United States. 1990; 110th edn. Washington, D.C.; 1990.

79. Seidman H, Silverberg E, Bodden A. Probabilities of eventually developing and dying of cancer. CA 1978; 28: 33-46.

80. Stamey TA. Cancer of the Prostate. Monogr Urol 1983; 68-91.

81. Pauker SG, Kassirer JP. Clinical decision analysis by personal computer. Arch Intern Med 1981; 141: 1831-1837.

82. Weinstein MC, Fineberg HV. Clinical Decision Analysis. Philadelphia, PA: WB Saunders; 1980.

83. Narayan P, Jajodia P. Prostatic oncology. Clin Geriatr Med 1990; 6: 131-161.

84. Lowe BA, Listrom MB. Incidental carcinoma of the prostate: an analysis of the predictors of progression. J Urol 1988; 140: 1340-1344.

85. Silverberg E. Statistical and epidemiological data on urologic cancer. Cancer 1987; 1 Aug. Suppl.: 692-717.

86. Austin J-P, Aziz H, Potters L et al. Diminished survival of young blacks with adenocarcinoma of the prostate. Am J Clin Oncol (CCT) 1990; 13: 465-469.

87. Mettlin C, Natarajan N. Epidemiologic observations from the American College of Surgeon's survey on prostate cancer. Prostate 1983; 4: 323-331.

88. Dayal HH, Chie C. Factors associated with racial differences in survival for prostate carcinoma. J Chron Dis 1982; 35: 553-560. 